\title{
A Compact UWB Microstrip Antenna with Modified Ground Plane for Bandwidth Enhancement
}

\author{
Bharti Gupta \\ Maulana Azad National \\ Institute of Technology \\ Bhopal M.P.
}

\author{
Sangeeta Nakhate \\ Maulana Azad National \\ Institute of Technology \\ BhopalM.P
}

\author{
Madhu Shandilya \\ Maulana Azad National \\ Institute of Technology \\ BhopalM.P
}

\begin{abstract}
This paper presents a bandwidth enhancing technique using a modified ground plane with diagonal edges, L-shaped slot and parasitic patches with main patch for the design of compact antennas. The proposed low-cost, compact-size rectangular patch antenna on $4.7 \mathrm{~cm} \times 3.6 \mathrm{~cm}$ printed circuit board (FR-4) is designed and validated through simulations and experiments. Results show that the ground plane with Lshaped slot in presence of the diagonal cuts at the top corners and the rectangular parasitic patches can increase the bandwidth. Return losses of $-23.6 \mathrm{~dB}$ and $-29.7 \mathrm{~dB}$ for the first and second resonant frequencies, respectively, can be achieved when the depth of the diagonal cut is $3 \mathrm{~mm}$, the dimension of each rectangular parasitic patch is 10 $\mathrm{mm} \times 3.5 \mathrm{~mm}$, and the L-shaped slot size is $7.5 \mathrm{~mm} \times 2.5 \mathrm{~mm}$, providing a $41.27 \%$ wider bandwidth than Federal Communication Commission's(FCC) standard.
\end{abstract}

\section{General Terms}

Designing of Microstrip Antenna.

\section{Keywords}

monopole antenna, quarter wavelength slot, parasitic patches, Ultra Wide Band.

\section{INTRODUCTION}

Although microstrip antennas have many attractive advantages, it has a narrow bandwidth. Maximum achievable data rate or capacity is related to the bandwidth and the signal-to-noise ratio through Shannon-Nyquist criterion $[1,2]$ :

$$
C=B \log _{2}(1+\mathrm{SNR})
$$

Where $\mathrm{C}$ is the maximum transmit data rate, $\mathrm{B}$ is for the channel bandwidth and SNR is the signal-to-noise ratio. From the above equation we can enhanced the transmit data rate by increasing either the bandwidth occupation or the transmission power. Many techniques have been used to enhance the bandwidth. Among these techniques are using thick foam or air substrates. Other techniques for enhancing the bandwidth of a single-layer single-patch microstrip antenna include the designs with a three-dimensional microstrip transition feed, a gap coupled feed, a capacitive coupled feed, an optimally designed impedance matching network , a chip-resistor loading, an integrated reactive loading[1]. etc. In addition the up-to-date applications require smaller antenna size in order to meet the miniaturization requirements of RF units .Many techniques have been used to obtain compact microstrip antenna, for example, adopting short-circuit pin (via holes), high dielectric constant substrate, and slots loaded on the patch.[2] However, the above methods for size reduction and extending the bandwidth emphasize microstrip antenna with thick substrates (from 3\% to $12 \%$ of working wavelength). Little research has been done to enhance the bandwidth and reduce the patch size with a thin substrate (less than $1 \%$ of working wavelength ) whereas developing ultralow-profile microstrip antenna with enhanced bandwidth and reduced size is very challenging in future integrated RF communication systems.

In this paper, we report a technique to enhance the bandwidth with rectangular patch antenna. The rectangular patch antenna with a $50-\Omega$ microstrip feed line is fabricated on the FR4 substrate.To improve the bandwidth, we modified the original ground plane to be $\mathrm{L}$-shaped with diagonal cuts at the top corners and rectangular parasitic patches with extra strip along with main patch. Applications of corner cut technique have been previously employed to improve the impedance bandwidth for microstrip patch antennas [3-7]. The simulation results of our proposed antenna are compared with the measured ones. The organization of the paper is as follows. The detail of the antenna design is in Section 2 . Preliminary results from simulations are described in Section 3. In section 4 discussion on the experimental results and conclusion in Section 5.

\section{ANTENNA DESIGN}

The geometries of the antennas in our study are shown in Figure 1. Microstrip antenna offers many advantages, such as being compact, economical, and light weight. On the other hand, it has some disadvantages such as lower bandwidth. Our main objective for the paper is to modify the physical structure and incorporate the techniques to enhance the bandwidth. We also analysis the parametric studies to achieve the optimum values of return loss and bandwidth.

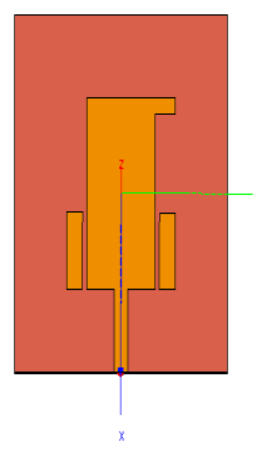

(a) 


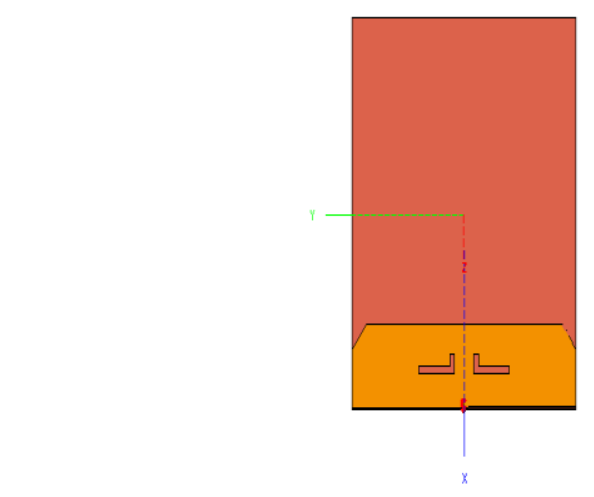

(b)

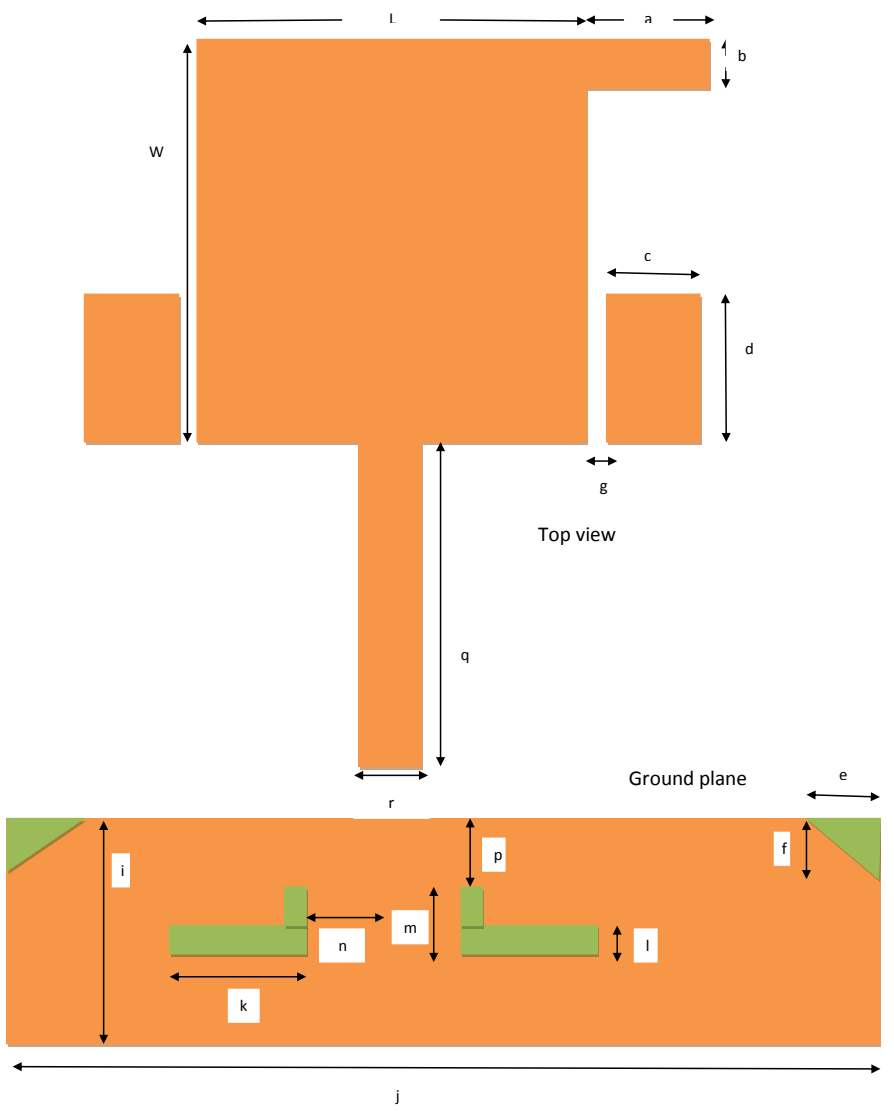

(c)

Figure 1: Geometries of the rectangular microstrip antennas (a)rectangular main patch (b)ground plane with diagonal edges and L-shaped slots.(c) Dimension of Proposed Antenna
The antenna configuration in Figure 1 is first used for the parametric study. The planar rectangular patch monopole is fabricated on a $4.7 \mathrm{~cm} \quad 3.6 \mathrm{~cm} \quad 0.16 \mathrm{~cm}$ FR-4 board

with a feed line and a finite ground plane. The gap of the rectangular patch antenna is the first parameter to optimize for the lowest return loss and widest bandwidth while the other parameters are kept constant. The width of the microstrip feed line is designed to be $3 \mathrm{~mm}$ for the impedance of $50 \Omega$.

\section{SIMULATION RESULTS}

The results in Figure 2 show that the increase of the gap will result in reductions of the return loss and the bandwidth. Even though the vertical gap of $11 \mathrm{~mm}$ provides the lowest return loss, we chose the radius of $10 \mathrm{~mm}$ for the better bandwidth.

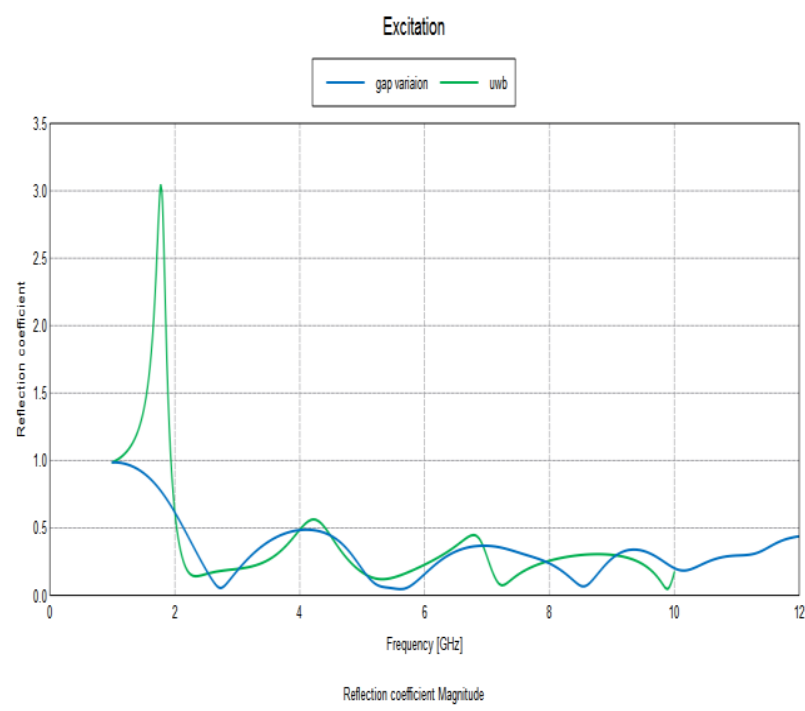

Figure 2: Return losses as functions of vertical gap.

The next parameter which is analyzed in the paper is width of the ground plane .The parameter is positive when the bottom of the patch is at the higher level than the top of the ground plane. The same can be said for the negative value of in the opposite direction. The results of the return loss and bandwidth as a function of the parameter are shown in Figure 3. Compared with the negative value of $i$, the positive value gives the higher return loss at high frequency while providing the lower return loss at low frequency. We chose the parameter $i$ to be zero (the bottom of the patch is at the same level as the top of the ground plane) for a compromise between the observed return loss at high and low frequencies. where the antenna is applicable from $2.957 \mathrm{GHz}$ to $11.892 \mathrm{GHz}$, providing a bandwidth of $8.935 \mathrm{GHz}$. 


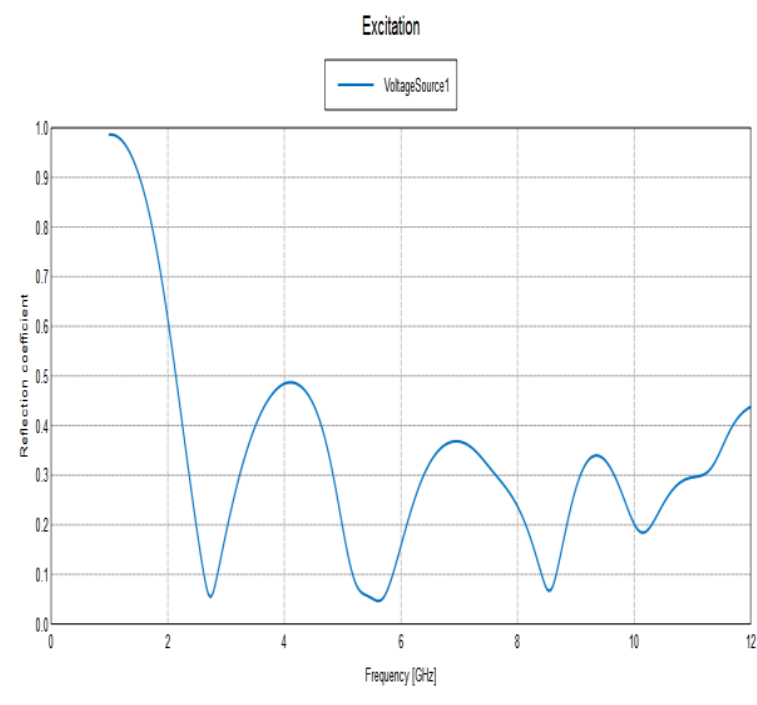

Refiection coefficient Magnitude - gap raniaion

Figure 3: Return losses as functions of width of ground

To further improve the bandwidth of the antenna, we removed the top corners of the ground plane, resulting in symmetrical diagonal edges. The resultant antenna is shown in Figure 1(b) with the parameter associated with the cut area. The return losses in Figure 4 show that the parameter only has a slight effect at low frequency while it has a significant effect at high frequency. The parameter of $3 \mathrm{~mm}$ seems to offer a relatively low return loss and an appropriately wide bandwidth. This antenna can be used from $2.957 \mathrm{GHz}$ to $12.1 \mathrm{GHz}$, providing a bandwidth of $9.15 \mathrm{GHz}$. Compared with the result in Figure 3, associated with the original shape, the antenna with diagonal edges on the ground plane can increase the bandwidth for approximately $0.21 \mathrm{GHz}$ as shown in Figure 5.

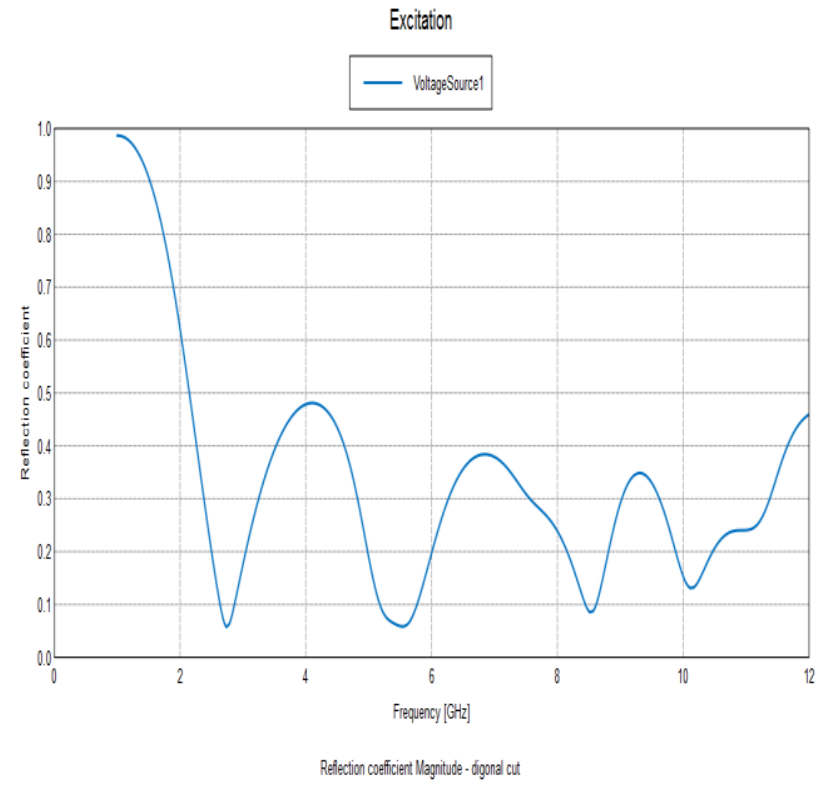

Figure 4: Return losses as a function of the parameter associated with the removed area on the ground plane.

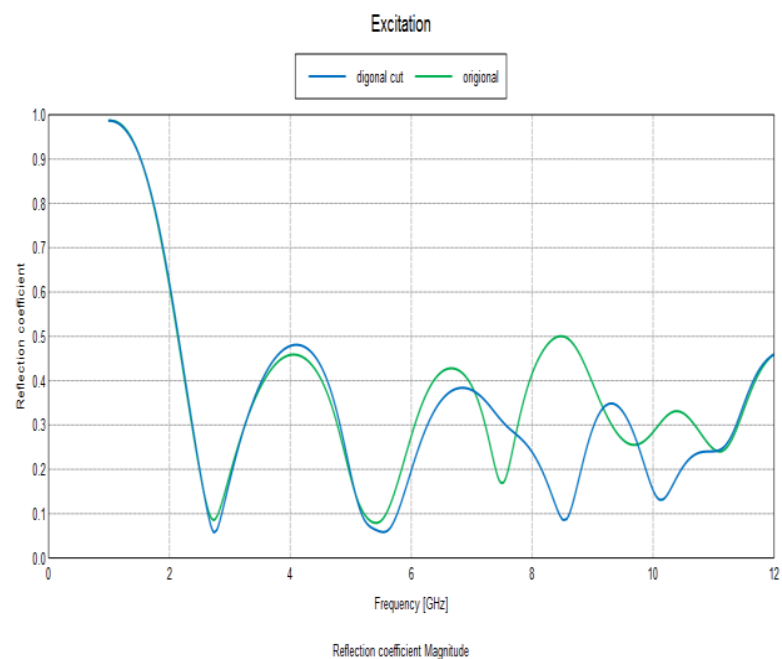

Figure 5: Comparison of return loss between the original antenna and the antenna with diagonal edges on the ground plane.

The L-shaped slot technique [8-12] is employed to improve the impedance matching in the UWB frequencies. This method introduces two identical slots at the center of the ground plane, shown in Figure 1(b), in order to moderate the reflection of the surface current, thus adjusting the antenna impedance and reducing the return loss[13-16]. The optimum values of the slot width and slot height are $7.5 \mathrm{~mm}$ and $2.5 \mathrm{~mm}$, respectively. The return losses of antenna with slot dimensions are shown in the Figure 6.

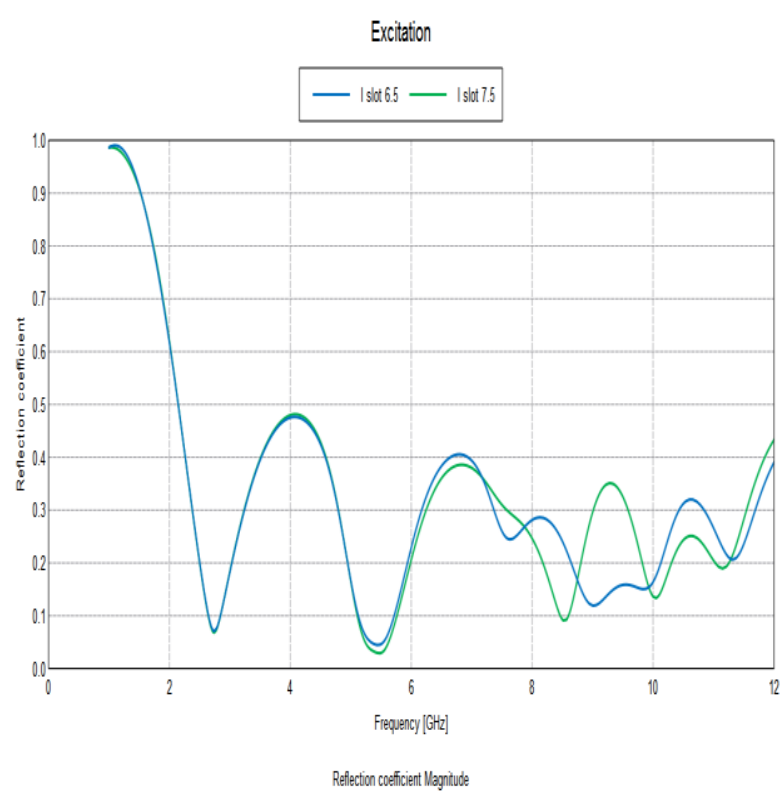

Figure 6: Return loss of antenna with slot dimension.

In addition to diagonal edges and L-shaped slots, the main patch was associated with parasitic patches (see Figure.1(b)) The results show that an accumulation of ground plane modifications and parasitic patch introduces an extra return loss dip, resulting in the optimal bandwidth. 


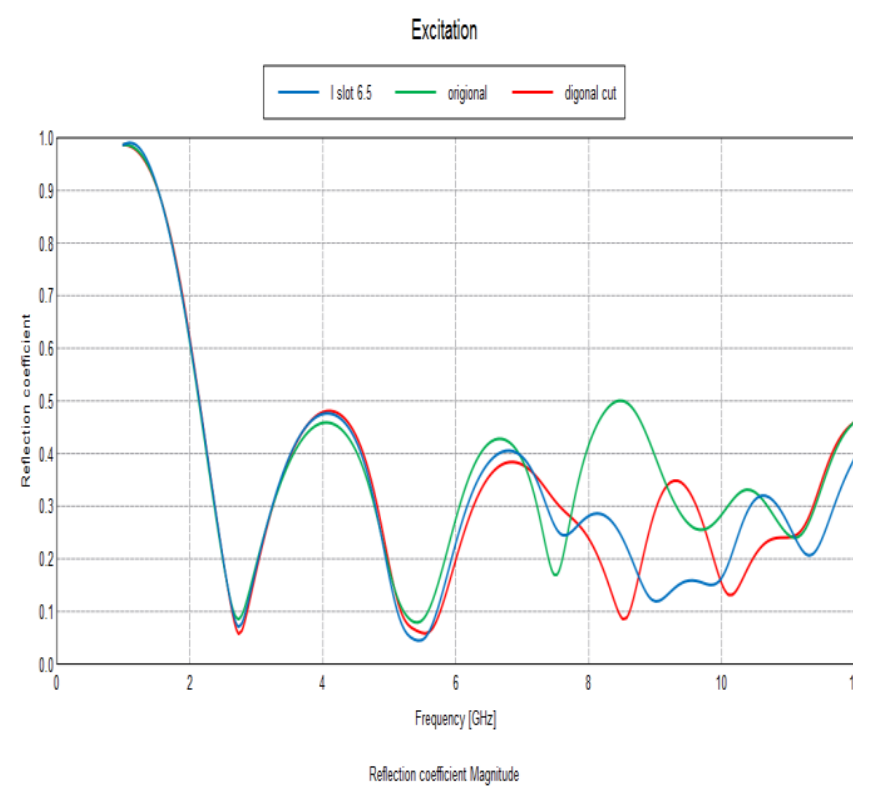

Figure 7: Comparison of return losses of all three configuration viz.original,diagonal cut,slots

\section{Table I Dimensions of Proposed Antenna}

\begin{tabular}{|l|l|}
\hline Symbol & $\begin{array}{l}\text { Size } \\
(\mathbf{m m})\end{array}$ \\
\hline $\mathrm{a}$ & 4.5 \\
\hline $\mathrm{b}$ & 2.0 \\
\hline $\mathrm{c}$ & 3.5 \\
\hline $\mathrm{d}$ & 10 \\
\hline $\mathrm{e}$ & 3.0 \\
\hline $\mathrm{f}$ & 3.0 \\
\hline $\mathrm{g}$ & 1.0 \\
\hline $\mathrm{G}$ & 1.0 \\
\hline $\mathrm{h}$ & 1.6 \\
\hline $\mathrm{i}$ & 10 \\
\hline $\mathrm{j}$ & 47 \\
\hline $\mathrm{k}$ & 7.5 \\
\hline $\mathrm{L}$ & 15 \\
\hline $\mathrm{l}$ & 1.0 \\
\hline $\mathrm{m}$ & 2.5 \\
\hline $\mathrm{n}$ & 2.0 \\
\hline $\mathrm{q}$ & 11 \\
\hline $\mathrm{r}$ & 3 \\
\hline $\mathrm{p}$ & 3.5 \\
\hline $\mathrm{W}$ & 25 \\
\hline & \\
\hline
\end{tabular}

\section{EXPERIMENTAL RESULT AND DISCUSSION}

The fabricated proposed rectangular patch antenna with diagonal edges and slots on the ground plane is shown in Figure 8 . The comparison between the simulated results using commercial high-frequency structure simulator (cadfeko 6.1) and the results from the measurement of the fabricated antenna using an Agilent VNA-L series N9923A vector network analyzer is shown in Figure 9. The measured result is relatively close to that obtained from simulation. The discrepancy of the return loss at the first resonant frequency would be caused by the measurement conditions between the simulation model and the fabrication .
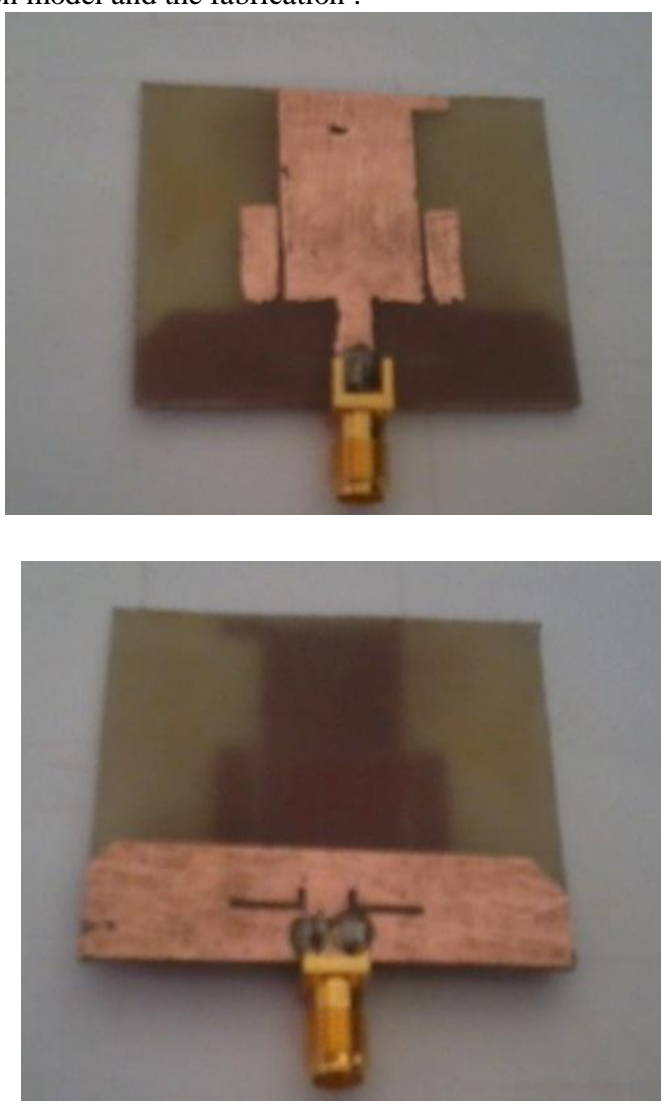

Figure 8: Photograph of the fabricated proposed antenna.

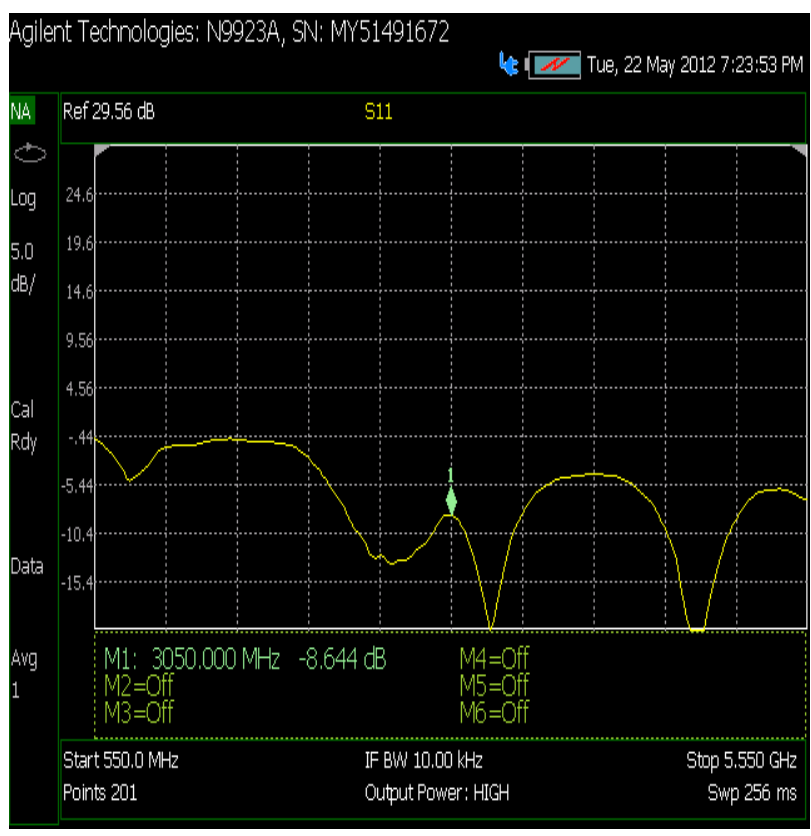

Figure 9:Measured Results 


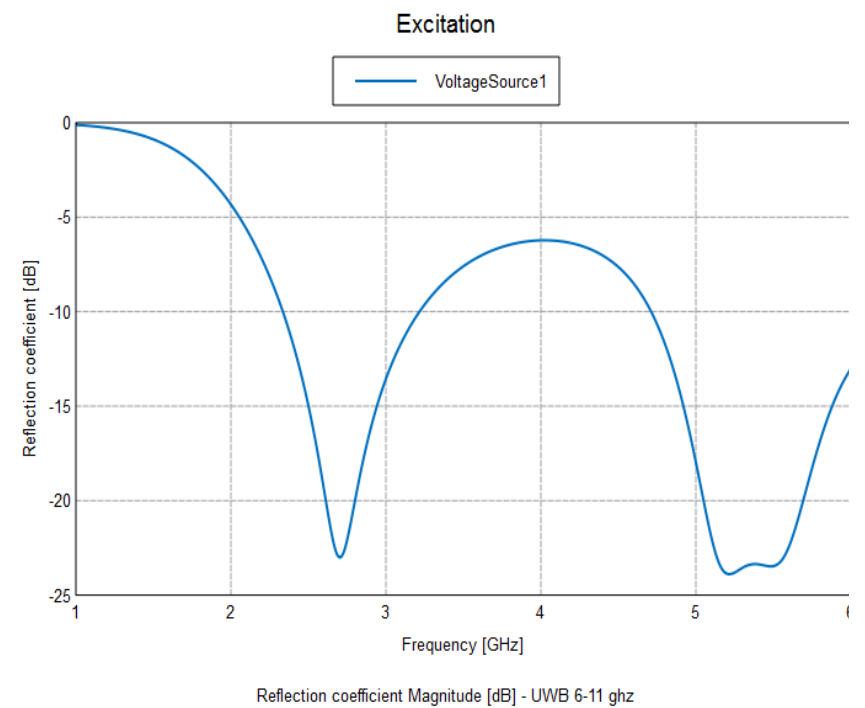

Figure 10: Comparison between simulated and measured results of the proposed rectangular microstrip antenna. The measured radiation patterns of the antenna on the E-plane and H-plane at resonant frequencies of $1 \mathrm{GHz}, 3 \mathrm{GHz}$, $6 \mathrm{GHz}$, and $8 \mathrm{GHz}$ are shown in Figures11,12 13 and 14 respectively. The results show that reasonable Omnidirectional radiation pattern can be observed along the $\mathrm{H}$ plane. The radiation pattern similar to that of the short dipole can be observed on the E-plane. Consistency of the patterns can also be observed across the operating frequencies. The Eplane co polarization patterns are bidirectional and H-plane co polarization patterns are Omni directional or nearly Omnidirectional at higher frequency, like a regular dipole [17]. When the frequency increases to $8 \mathrm{GHz}$, the direction of the electric field becomes complex. As a result, the crosspolarization level rises and ripples appear in the E-plane but the H-plane is still omni-directional. As a conclusion, the radiation pattern of the proposed antenna is almost stable in the operation band (3-12 GHz). Figure 17 shows the relatively almost constant gain of optimized antenna from 1 to $6 \mathrm{GHz}$ with some changes about $5.5 \mathrm{GHz}$.and this gain is not nearly change but it seem to be reduced at the higher frequency.

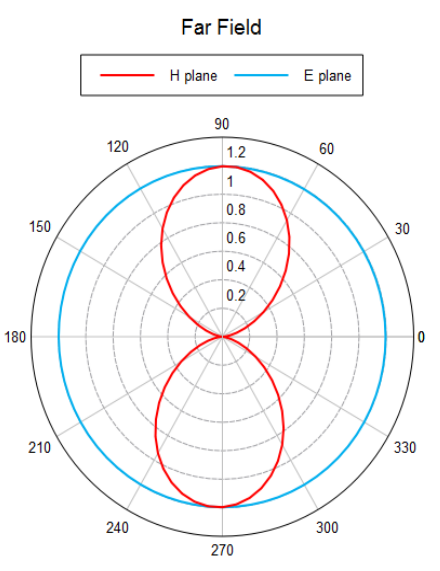

Total Gain (Frequency $=1 \mathrm{GHz}$; Theta $=90 \mathrm{deg}$; Phi $=90 \mathrm{deg}$ ) - uwb

Figure 11: simulated radiation patterns at 1 GHz. (a) Eplane patterns, and (b) H-plane patterns.

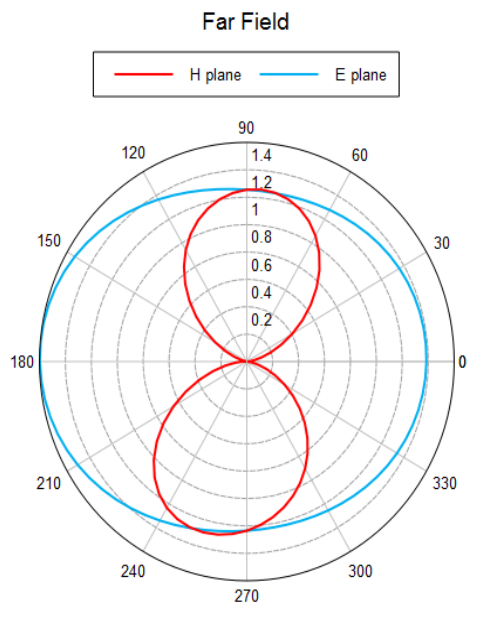

Total Gain (Frequency $=3 \mathrm{GHz}$; Theta $=90 \mathrm{deg} ;$ Phi $=90 \mathrm{deg})-\mathrm{uwb}$

Figure 12:simulated radiation patterns at 3 GHz. (a) Eplane patterns, and (b) H-plane patterns.

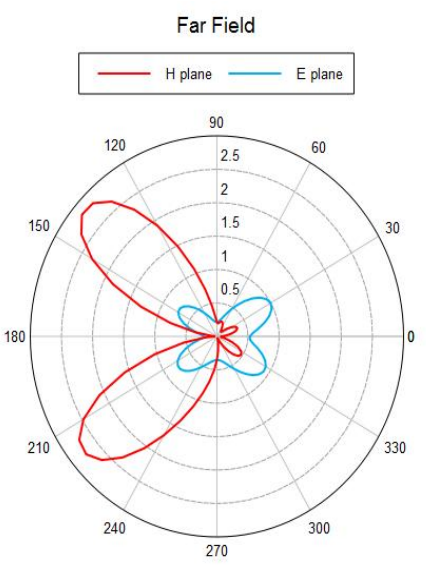

Total Gain (Frequency $=6 \mathrm{GHz}$; Theta $=90 \mathrm{deg} ;$ Phi $=90 \mathrm{deg}$ ) - uw

Figure 13: simulated radiation patterns at 8GHz. (a) Eplane patterns, and (b) H-plane patterns

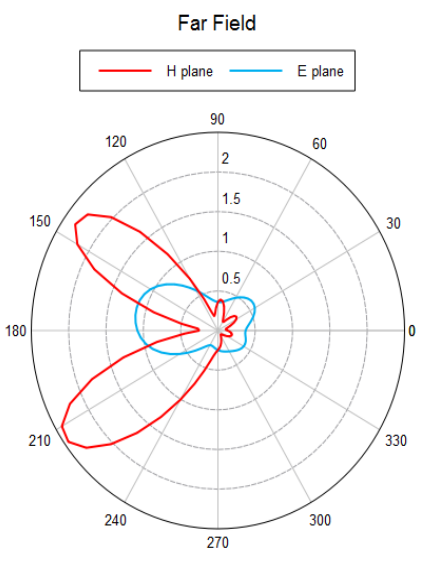

Total Gain (Frequency $=8 \mathrm{GHz}$; Theta $=90 \mathrm{deg} ;$ Phi $=90 \mathrm{deg})$ - uw

Figure 14: simulated radiation patterns at $8 \mathrm{GHz}$. (a) Eplane patterns, and (b) H-plane patterns. 


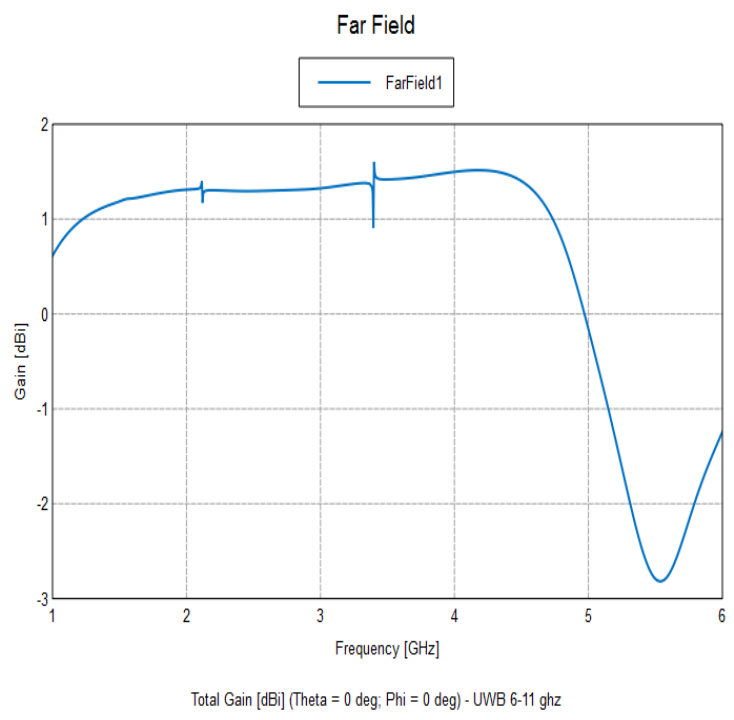

Figure 15: Gain of the optimized antenna

Several important observations from the results of the return loss are detailed as follows. First, the dimension of the rectangular patch basically corresponds to the quarter wavelength of the associated resonant frequency [18, 19]. In addition, the parameter results in not only the resonant frequency shifting but also the return loss level between the first and second resonant frequencies. For the second observation, the first resonance is barely changed for all different ground plane sizes as shown in Figures 3 When the ground plane is reduced in either length or width, the first resonant frequency is shifted slightly at around $3 \mathrm{GHz}$. These two observations imply that the resonant frequency is typically determined by the rectangular microstrip antenna size and slightly detuned by the size of the ground plane. The observation is that, as shown in Figure 2, the first resonant frequency is dependent on the size of the rectangular microstrip antenna as mentioned above while the second resonant frequency and the bandwidth obey the dimension of the cut area at the ground plane corners [20, 21]. The rectangular L- slot and diagonal cut are used to improve the impedance matching of the propose antenna to reduce the reflection of surface current, thus adjusting the parameters of slot cut to reduce return loss or enhance the bandwidth of UWB antenna.

\section{CONCLUSION}

A compact antenna and a technique to increase its bandwidth have been proposed and implemented. The proposed low-cost and compact-size rectangular patch antenna on $4.7 \mathrm{~cm} \times$ $3.6 \mathrm{~cm}$ printed circuit board (FR-4) is designed and validated through simulations and experimental observations. Results show that the bandwidth can be tuneable depending mainly on the L-slot size and the vertical gap between the patch and the ground plane. With the presence of the diagonal cut areas at the corners of the ground plane, the bandwidth can be further improved. Return losses of $-17 \mathrm{~dB}$ and $-30 \mathrm{~dB}$ for the first and second resonant frequencies, respectively, can be achieved when the depth of the diagonal cut is at optimum value . providing a maximum $41.27 \%$ wider bandwidth (3.1$10.6 \mathrm{GHz}$ ) than the FCC recommended standard of 3.110.6 GHz. Finally, the size of the ground plane, which has an insignificant impact on the performance, can be further reduced to meet a compact size design.

\section{REFERENCES}

[1] J. G. Proakis, Digital Communications, McGraw-Hill, New York, NY, USA, 1989.

[2] C. E. Shannon, "A mathematical theory of communication," The Bell System Technical Journal, vol. 27, pp. 379-423, 623-656, 1948.

[3] Z. N. Chen, "small printed Ultrawideband Antenna With Reduced Ground Plane," IEEE transactions on antennas and propagation, vol. 55, no. 2, february 2007, 383 .

[4] Hindawi Publishing CorporationInternational Journal of Microwave Science and Technology Bandwidth Enhancement of UWB Microstrip Antenna with a Modified Ground Plane N. Prombutr,1 P. Kirawanich,1 and P. Akkaraekthalin 2. Volume 2009, Article ID 821515,7pages doi:10.1155/2009/821515 Research Article

[5] A. K. Sharma and A. Mittal, "Diagonal slotted diamond shaped dual circularly polarized microstrip patch antenna with dumbbell aperture coupling," in Proceedings of the 8th European Conference on Wireless Technology, pp. 463-465, 2005 .

[6] N. Prombutr, J. Pakeesirikul, T. Theatmongkol, and S. Suangool, "Dual-band coplanar waveguide antenna design by using U-slot with diagonal edge," in Proceedings of the 21st International Technical Conference on Circuits/Systems, Computers and Communications, vol. 3, pp. 117-120, Chaingmai, Thailand, 2006.

[7] M. A. Alkanhal and A. F. Sheta, "A novel dual-band reconfigurable square-ring microstrip antenna," Progress in Electromagnetics Research, vol. 70, pp. 337-349, 2007.

[8] F. G. Kharakhili, M. Fardis, G. Dadashzadeh, A. Ahmadi, and N. Hojjat, "Circular slot with a novel circular microstrip open ended microstrip feed for UWB applications," Progress in Electromagnetics Research, vol. 68, pp. 161-167, 2007.

[9] Y. Song, Y.-C. Jiao, G. Zhao, and F.-S. Zhang, "Multiband CPW-FED triangle-shaped monopole antenna for wireless applications," Progress in Electromagnetics Research, vol. 70, pp. 329-336, 2007.

[10] S. Sadat, M. Houshmand, and M. Roshandel, "Design of a microstrip square-ring slot antenna filled by an H-shape slot for UWB applications," Progress in Electromagnetics Research, vol. 70, pp. 191-198, 2007

[11] J.-J. Jiao, G. Zhao, F.-S. Zhang, H.-W. Yuan, and Y.-C. Jiao, "A broadband CPW-FED T-shape slot antenna," Progress in Electromagnetics Research, vol. 76, pp. 237242, 2007.

[12] R. Zaker, Ch. Ghobadi, and J. Nourinia, "A modified microstrip-fed two-step tapered monopole antenna for UWB and WLAN applications," Progress in Electromagnetics Research, vol. 77, pp. 137-148, 2007.

[13] S. L. S. Yang, K. F. Lee, A. A. Kishk, and K. M. Luk, "Design and study of wideband single feed circularly 
polarized microstrip antennas," Progress in Electromagnetics Research, vol. 80, pp. 45-61, 2008.

[14] Y. Yang, Y. Wang, and A. E. Fathy, "Design of compact vivaldi antenna arrays for UWB see through wall applications," Progress in Electromagnetics Research, vol. 82, pp. 401-418, 2008.

[15] R. Fallahi, A.-A. Kalteh, and M. G. Roozbahani, "A novel UWB elliptical slot antenna with band-notched characteristics," Progress in Electromagnetics Research, vol. 82, pp. 127-136, 2008.

[16] M. Abbaspour and H. R. Hassani, "Wideband star-shaped microstrip patch antenna," Progress in Electromagnetics Research Letters, vol. 1, pp. 61-68, 2008.

[17] X.-C. Yin, C.-L. Ruan, C.-Y. Ding, and J.-H. Chu, "A planar u type monopole antenna for uwb applications," Progress in Electromagnetics Research Letters, vol. 2, pp. 1-10, 2008.
[18] Q. Liu, C.-L. Ruan, L. Peng, and W.-X. Wu, "A novel compact archimedean spiral antenna with gap-loading," Progress in Electromagnetics Research Letters, vol. 3, pp. 169-177, 2008

[19] A. Danideh, R. Sadeghi-Fakhr, and H. R. Hassani, "Wideband co-planar microstrip patch antenna," Progress in Electromagnetics Research Letters, vol. 4, pp. 81-89, 2008.

[20] M. Albooyeh, N. Komjani, and M. Shobeyri, "A novel cross-slot geometry to improve impedance bandwidth of microstrip antennas," Progress in Electromagnetics Research Letters, vol. 4, pp. 63-72, 2008.

[21] G.-P. Gao, X.-X. Yang, J.-S. Zhang, and J.-X. Xiao, “A printed volcano smoke antenna for UWB and WLAN communications," Progress in Electromagnetics Research Letters, vol. 4, pp. 55-61, 2008. 